\title{
Solvent Diffusion Method: An Effective Approach to Formulate Nanosponges Loaded with Naproxen Sodium
}

Fizza llyas, Muhammad Jamsahid, Irfan Bashir, Rabia Aslam*, Tooba Mehboob, Naila Tabassam, Muhammad Nadeem Alvi

University of Central Punjab, Lahore, Pakistan \begin{abstract}
(1)
Authors' Contributions

3, 4, 7 Conception \& study design

1, 5, 6 Data Collection \& Processing

2, 4 Data Analysis and/or interpretation

1, 5, 6 Drafting of Manuscript

2, 3, 7 Critical Review
\end{abstract}

\section{Acknowledgement}

Prof Dr Muhammad Jamshaid for his guidance and supports.

Article info.

Received: October 25, 2019

Accepted: September 10, 2020

Funding Source: Nil

Conflict of Interest: Nil

Cite this article: llyas F, Jamsahid M, Bashir

I, Aslam R, Mehboob T, Tabassam N, Alvi MN. Solvent Diffusion Method: An effective

approach to formulate nanosponges loaded with naproxen sodium. RADS J Pharm Pharm Sci. 2020; 8(2):74-80.

*Address of Correspondence Author: rabiaaslam96@gmail.com

\section{ABSTRACT}

Objective: Solubility of naproxen sodium is limited. In conventional dosage form it causes different gastro intestinal problems. To overcome these difficulties naproxen sodium loaded nano sponges were designed.

Methodology: Nanosponges were formulated by using emulsion solvent evaporation technique. To obtain dispersion of nanosponges, homogenization of active drug, with specified quantities of polyvinyl alcohol, dichloromethane, ethyl cellulose and distilled, water was done. Compatibility among excipients and active drug was checked by FTIR and results didn't show any interaction between them. 11 trial formulations were tested for poly dispersity, zeta potential, particle size and viscosity.

Results: Results showed all formulations except NS9, NS10 and NS11 were in nano range. Formulation NS1 to NS6 fall in category of "mid poly dispersity" and formulation NS7 to NS11 were in the category of "very poly dispersity". Values of Zeta potential of all formulations were in negative range -0.106 to $9.75 \mathrm{mV}$. The value of viscosity of all formulations were 0.8872 . NS2 and NS3 were selected for further testing like Franz cell diffusion study, stability testing and drug loading efficiency. In Franz cell diffusion study, drug release for NS2 $=89.62 \%$, for NS3 $=89.10 \%$ at 50 minutes' time. Stability studies performed for the 21 days, NS2 and NS3 revealed slight change in percentage drug content at $4{ }^{\circ} \mathrm{C}$ and $25^{\circ} \mathrm{C}$, and major changes were observed at $45^{\circ} \mathrm{C}$ temperature. Drug loading efficiency was found in NS2 $=97.659 \%$ and for $\mathrm{NS} 3=98.901 \%$.

Conclusion: Nanosponges formulations loaded with naproxen sodium have successfully been prepared.

Keywords: Zeta potential, naproxen sodium, solvent diffusion method, nanosponges.

\section{INTRODUCTION}

Nano sized colloidal carriers recently gained much importance in drug delivery system by improving the release pattern (prolonged release) of poor water soluble drugs [1] . Nano technology offers enhanced efficacy to drug products in comparison with conventional techniques [2]. Utilization of nano technology, in the form of different nanoparticles, photodynamic therapy and nanotechnology based hyperthermia, improves the cancer therapy [3-5]. The size of nanosponges is very small as they can be compared with the size of viruses. Due to their size, they can be incorporated with the wide range of 
drugs. Drud releasing mechanism from nanosponges is predictable and well controlled. They keep on circulating in body until they reach to the specific site,they get attached to the targeted site and release durg. This property can be more effectively utilized in targeted drug delivery. High aqueous solubility is another prominent feature of nanosponges. Drugs having poor water solubility can be conveniently used with these tiny sponges. They are like three dimensional frame work or scaffold having long chain of polyester as a back bone of structure. To unite different parts of polymers together it is treated with cross linkers in a solution, which act like grapping hooks. The product of this reaction is spherical shaped particles having no of cavities in which drug can be loaded easily. Biodegradable nature of polyester allows its gradual breakdown in body [6]. Nanosponges have average diameter of less than 1 $\mu \mathrm{m}$ [7]. To be loaded in nanosponges, the molecular weight of drug should fall in the range of $100-400 \mathrm{D}$ and molecular structure should not contain more than 5 condensed rings. Melting point for drug to be loaded in nanosponges should be $250^{\circ} \mathrm{C}$ and less water solubility than $10 \mathrm{mg} / \mathrm{ml}$. Naproxen sodium, that pharmacologically belongs to NSAID and bio pharmaceutically to class II drugs, considered best candidate among drugs for nanosponges [8]. Nanosponges can be prepared by, solvent technique, emulsion solvent diffusion technique [9], and preparation of nanospnges by hyper cross-linked $\beta$ cyclodextrins [10].

\section{MATERIALS AND METHODS}

\section{Materials}

Dichloromethane $\left(\mathrm{CH}_{2} \mathrm{Cl}_{2}\right)$, naproxen sodium $\left(\mathrm{C}_{14} \mathrm{H}_{13} \mathrm{NaO}_{3}\right)$, poly-vinyl alcohol $\left(\mathrm{C}_{2} \mathrm{H}_{4} \mathrm{O}\right) \mathrm{x}$ ) and ethyl cellulose $\left(\mathrm{C}_{20} \mathrm{H}_{38} \mathrm{O}_{11}\right)$ were obtained from Razi Pharmaceuticals.

\section{Composition of trials Formulation}

Different formulations formed during experimentation are tabulated in Table 1.

\section{Formulation of Naproxen Sodium Loaded Nanosponges.}

Naproxen sodium (200 mg) and ethyl cellulose (200 $\mathrm{mg}$ ) were taken. Dichloromethane $(20 \mathrm{ml})$ were then mixed with above mixture. Poly vinyl alcohol (2200 $\mathrm{mg}$ ) was dissolved in $\mathrm{DI}$ water $(10 \mathrm{ml})$ which were then added in previously made mixture with continuous stirring. To make the mixture homogenized Heidolph Silent crusher M (EU) were used for 20 minutes at $6000 \mathrm{rpm}$. As a result Nanosponge emulsion was formed [11-12]. Whole method was repeated by varying the amount of ethyl cellulose and poly vinyl alcohol as mentioned in

Table 1.

Table 1. Compositions of the Trials.

\begin{tabular}{|c|c|c|c|c|c|}
\hline $\begin{array}{c}\text { Trails } \\
\text { Formulations }\end{array}$ & $\begin{array}{c}\text { Ethyl cellulose } \\
(\mathbf{m g})\end{array}$ & $\begin{array}{c}\text { Water } \\
(\mathbf{m l})\end{array}$ & $\begin{array}{c}\text { Naproxen Sodium } \\
(\mathbf{m g})\end{array}$ & $\begin{array}{c}\text { DCM } \\
(\mathbf{m l})\end{array}$ & $\begin{array}{c}\text { PVA } \\
(\mathbf{m g})\end{array}$ \\
\hline 1. & 200 & 10 & 100 & 20 & 2200 \\
\hline 2. & 400 & 10 & 100 & 20 & 2000 \\
\hline 3. & 600 & 10 & 100 & 20 & 1800 \\
\hline 4. & 800 & 10 & 100 & 20 & 1600 \\
\hline 5. & 1000 & 10 & 100 & 20 & 1400 \\
\hline 6. & 1200 & 10 & 100 & 20 & 1200 \\
\hline 7. & 1400 & 10 & 100 & 20 & 1000 \\
\hline 8. & 1600 & 10 & 100 & 20 & 800 \\
\hline 9. & 1800 & 10 & 100 & 20 & 600 \\
\hline 10. & 2000 & 2200 & 100 & 20 & 400 \\
\hline 11. & & 100 & 20 & 200 \\
\hline
\end{tabular}




\section{Characterization of Naproxen Sodium Loaded Nanosponges Fourier transform infrared spectroscopy}

FTIR was executed to evaluate the potential interaction between excipients and active drug at wavelength ranging from $4000-650 \mathrm{~cm}-1$ which was carried out at G.T pharmaceuticals.

\section{Particle size and poly-dispersity (PDI)}

Particle size and poly-dispersity were calculated using Malvern zeta-sizer Nano ZSP at Lahore University of Management Sciences (LUMS).

Poly-dispersity index (PDI) can be evaluate by equation given below,

$$
\text { Poly dispersity index }=\frac{\Delta \mathrm{d}}{d_{\text {avg }}}
$$

Where,

$\Delta \mathrm{d}=$ distribution width is indicated as $\mathrm{SD}$

$\mathrm{d}_{\text {avg }}=$ average particle size indicated as MV $(\mathrm{nm})$

Types of dispersion are categorized in term of PDI are below,

0-0.05 (PDI) represents Monodisperse standard, 0.05-0.08 (PDI) represents Nearly monodisperse, while 0.08-0.7 denotes Mid-range poly-dispersity and $>0.7$ symbolize Very poly-disperse (6).

\section{Zeta potential}

Zeta potential is substantial feature of electrical double layer, it can be calculated using Malvern zetasizer Nano ZSP with the addition of an electrodes [13-14].

\section{Viscosity \\ Viscosity was also calculated using Malvern zetasizer.}

\section{Drug loading efficiency}

Calculation of drug loading efficiency was done by employing following method:

$1 \mathrm{ml}$ of sample was taken from NS2 and NS3 and centrifuged using ultra centrifuge at speed of 45000 rpm for about 10 minutes. $4.5 \mathrm{ml}$ of phosphate buffer having $\mathrm{pH}$ of 7.4 was added in $0.5 \mathrm{ml}$ of supernatant (obtained from centrifuged mixture). Then absorbance was checked using UV spectrophotometer (HALO DB-20 UV-VIS double beam spectrophotometer) at $\lambda_{\max }$ of $272 \mathrm{~nm}$. Following formula was used to calculate the Percentage drug content:
Percentage Content $=\frac{\text { Absorbance of trial preparation }}{\text { Absorbance of standard }} \times 100$

\section{Diffusion study of drug}

Diffusion study of drug was performed in UOL (Lahore Campus) through Franz Diffusion cell by employing method given below:

$170.275 \mathrm{mg}$ of the sample containing approximately $0.5 \mathrm{mg}$ of the active ingredient was separately taken out of NS2 trial formulation and NS3 trial formulations and positioned on a dialysis membrane of Franz's diffusion cell. Phosphate buffer of $\mathrm{pH} 7.4$ was added in Franz cell which was then positioned in water bath at temperature of about $25^{\circ} \mathrm{C}$. Samples were taken out after 5 minutes time interval up to $50 \mathrm{~min}$. Fresh buffer was added to maintain the sink condition. Absorbance of obtained samples was calculated at $\lambda_{\max } 272 \mathrm{~nm}$ by UV spectrophotometer. Then these values were used to calculate the percentage content of drug diffusion using:

$$
\% \text { Age Content }=\frac{\text { Absorbance of trial preparation }}{\text { Absorbance of standard }} \times 100
$$

\section{Stability studies}

Stability of any drug is basically its capability to preserve its quality, purity, identity, and its strength in test duration or till the date of expiry. Its critical process by which we determine the shelf life of product [15]. Following procedure was performed for calculating stability:

The samples of trial formulation NS2 and trial formulation NS3 were kept at different temperature of $4^{\circ} \mathrm{C}, 25^{\circ} \mathrm{C}$ and $45^{\circ} \mathrm{C}$ in refrigerator, room temperature and oven respectively. Minute quantities of samples were withdrawn at different days i.e. 1, 2, 7, 14, 21. Then these samples were centrifuged for $10 \mathrm{~min}$ at $45000 \mathrm{rpm} .0 .5 \mathrm{ml}$ of supernatant was taken from centrifuged sample and added in $4.5 \mathrm{ml}$ of phosphate buffer of $\mathrm{pH}$ 7.4. Absorbance was recorded at $\lambda_{\max }$ $272 \mathrm{~nm}$. These values were used to find the amount of drug present in samples after above mentioned days, by applying following formula:

$$
\% \text { Age Content }=\frac{\text { Absorbance of trial preparation }}{\text { Absorbance of standard }} \times 100
$$




\section{RESULT AND DISCUSSION}

\section{Fourier Transform Infrared Spectroscopy}

Fourier transform infrared spectroscopy i.e. FTIR is one of the most valuable technique for structural evaluation [16] so that a comparison between drug- polymer and polymer-polymer measured to improve the properties compare to individual [17]. FTIR studies of naproxen sodium and its trial formulation was performed in G.T Pharmaceuticals Pakistan. The results did not indicate interaction between drug and excipients. The peaks that obtained after FTIR were shown in Figure 1 and Figure 2.

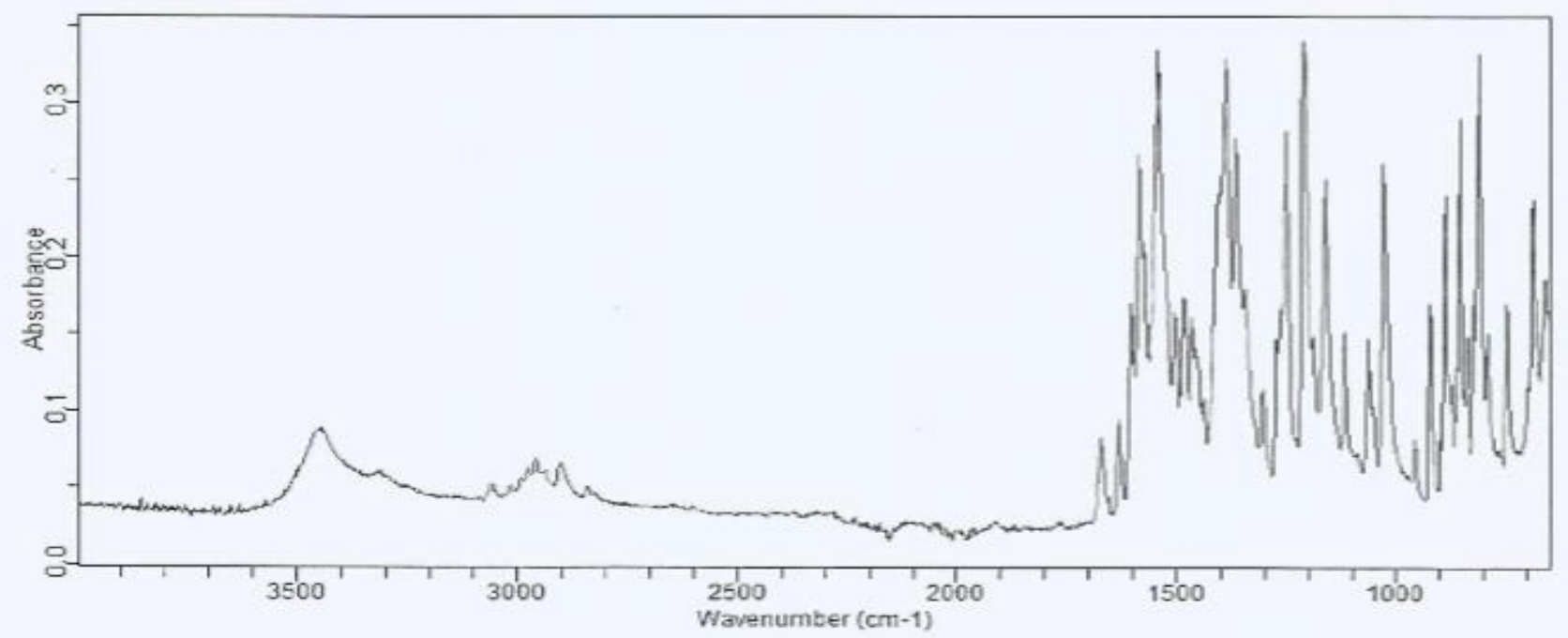

Figure 1. FTIR Studies of Naproxen Sodium.

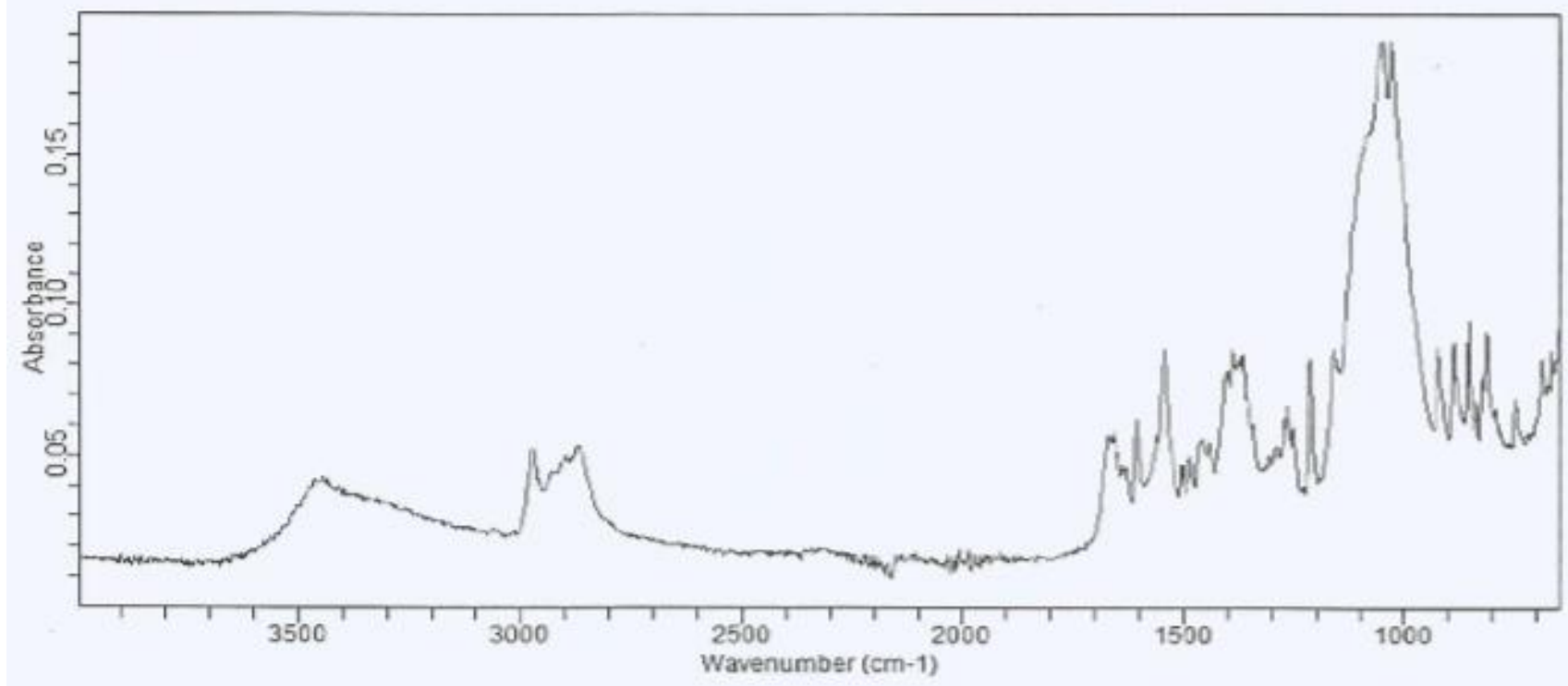

Figure 2. FTIR Studies of Formulation.

\section{Post-Formulation Characterizations}

Polyvinyl alcohol dichloromethane, distilled water and ethyl cellulose were used for the preparation of nanosponges of naproxen sodium (NS). From this, 11 formulations were prepared and out of these 9 formulations were tested for determination of particle size, viscosity, zeta potential and polydispersity, index. The results of these tests are given in Table 2 
Table 2. Particle size, viscosity, zeta potential, polydispersity index and of nanosponges loaded with naproxen sodium.

\begin{tabular}{|c|c|c|c|c|}
\hline Trial Formulation I.D & $\begin{array}{c}\text { Particle Size } \\
\mathbf{( d ~} \mathbf{~} \mathbf{)}\end{array}$ & Viscosity $\mathbf{( c p )}$ & $\begin{array}{c}\text { Zeta Potential } \\
\mathbf{( m V})\end{array}$ & Poly-Dispersity index \\
\hline NS1 & $21.30 \pm 0.02$ & $0.8872 \pm 0.0001$ & $-0.567 \pm 0.001$ & $0.302 \pm 0.001$ \\
\hline NS2 & $12.60 \pm 0.01$ & $0.8872 \pm 0.0001$ & $-3.96 \pm 0.02$ & $0.225 \pm 0.001$ \\
\hline NS3 & $33.14 \pm 0.01$ & $0.8872 \pm 0.0001$ & $-7.20 \pm 0.01$ & $0.445 \pm 0.001$ \\
\hline NS4 & $32.47 \pm 0.01$ & $0.8872 \pm 0.0001$ & $-6.53 \pm 0.01$ & $0.254 \pm 0.002$ \\
\hline NS5 & $29.52 \pm 0.02$ & $0.8872 \pm 0.0001$ & $-2.40 \pm 0.02$ & $0.398 \pm 0.001$ \\
\hline NS6 & $19.82 \pm 0.01$ & $0.8872 \pm 0.0001$ & $-5.84 \pm 0.02$ & $0.308 \pm 0.002$ \\
\hline NS7 & $126.7 \pm 0.01$ & $0.8872 \pm 0.0001$ & $-2.86 \pm 0.01$ & $0.844 \pm 0.002$ \\
\hline NS8 & $159.3 \pm 0.02$ & $0.8872 \pm 0.0001$ & $-9.75 \pm 0.02$ & $0.318 \pm 0.001$ \\
\hline NS9 & $1021 \pm 0.02$ & $0.8872 \pm 0.0001$ & $-6.62 \pm 0.02$ & $0.810 \pm 0.002$ \\
\hline NS10 & $1589 \pm 0.02$ & $0.8872 \pm 0.0001$ & $-0.154 \pm 0.002$ & $1.030 \pm 0.002$ \\
\hline NS11 & $1842 \pm 0.02$ & $0.8872 \pm 0.0001$ & $-0.106 \pm 0.002$ & $1.393 \pm 0.002$ \\
\hline
\end{tabular}

\section{Particle size}

The range of particle size of nanosponges is 21.301021, revealed that particle size of all formulations was in nano range. The results of particle size analysis revealed non linearity between first three formulations (NS1, NS2 \&NS3). The size of NS1 formulation was greater and NS2 was smaller. Then particle size further increased for formulation of NS3. After that the particle size started to decrease gradually till NS6 formulation and rapidly increased to NS11 trial. Thereby, formulations of NS9, NS10 and NS11 were removed from the nanosponges as their particle sized fall in the range of micrometer. The values of " $P>F$ " less than 0.0500 indicate significance of model term. In this scenario the significance of model terms was zero as values were greater than 0.1000 . In such scenario model reduction method might improve the significance of model. A negative value of "Pred R-Squared" represent that total mean was a better indicator of test response than the current model.

\section{Polydispersity index}

Poly dispersibility index is the index that showed variations among particle size distribution [18]. All the tested formulation of nanosponges fall within the middle range of polydispersity index in contrast to formulation NS7-NS11 as there ranges were according to the poly dispersibility index chart (6).

\section{Viscosity}

The result of Viscosity of every formulation is 0.8872 .

\section{Zeta-potential}

For determination of zeta potential were performed at LUMS, Pakistan, by Malvern zeta-sizer [19]. The value of zeta-potential for tested formulations were found to be negative. The range of zeta potential testing was $-0.106 \ldots-9.75$.

\section{Drug encapsulation efficacy}

The drug efficacy in nanoparticle drug delivery system depend upon the ability of a drug to release within the proximity of drug action site at appropriate time. Thereby the encapsulation efficiency is most important phenomenon in case of nanosponges [20]. Formulation NS2 \& NS3 were tested to verify the amount of drug loaded within nanosponges. The result revealed amount of drug in NS2 formulation was 97.659 and for NS3 was 98.901. The encapsulation efficacy of NS3 is more than NS2 which may be due the highest cross-linking between the polymers allowing more drug to be entrapped in a nanosponge. 
Franz cell diffusion studies Diffusion studies were performed for formulation NS2 and NS3.The results shows that the percentage of drug release was slightly higher in NS3 formulation as compared to NS2. It may be attributed to the changes in the concentrations of PVA and EC. The values of \%age content released VS time were discussed in Table $\mathbf{3}$. The graph plotted between time and rate of diffusion was specified in Figure 3.

Table 3. Franz cell diffusion studies.

\begin{tabular}{|c|c|c|}
\hline NS2 & Time & NS3 \\
\hline 60.794 & $1 \mathrm{~min}$ & 61.961 \\
\hline 62.33 & $5 \mathrm{~min}$ & 63.29 \\
\hline 64.26 & $10 \mathrm{~min}$ & 65.31 \\
\hline 66.20 & $15 \mathrm{~min}$ & 67.99 \\
\hline 67.17 & $20 \mathrm{~min}$ & 69.84 \\
\hline 69.59 & $25 \mathrm{~min}$ & 72.83 \\
\hline 73.00 & $30 \mathrm{~min}$ & 74.92 \\
\hline 75.27 & $35 \mathrm{~min}$ & 76.77 \\
\hline 79.14 & $40 \mathrm{~min}$ & 78.61 \\
\hline 83.49 & $45 \mathrm{~min}$ & 81.95 \\
\hline 89.62 & $50 \mathrm{~min}$ & 89.10 \\
\hline
\end{tabular}

Figure 3. Franz Cell Diffusion Studies for NS2 and NS3.

\section{Stability Testing}

Stability studies were conducted for the time period of 21 days for two formulation NS2 and NS3. The percentage drug content was slightly affected at temperature $4^{\circ} \mathrm{C}$ and $25^{\circ} \mathrm{C}$ but as temperature increased to $45^{\circ} \mathrm{C}$, major changes in \% drug content was observed. The results showed that there were no changes in physical appearance when compared with the freshly prepared formulation but when it comes to percentage drug content slight changes were seen at temperature $4^{\circ} \mathrm{C}$ and $25^{\circ} \mathrm{C}$ but as temperature increased to $45^{\circ} \mathrm{C}$, major changes in \% drug content was observed. The results of the above mentioned changes were compiled in Table 4.

Table 4. Stability Testing.

\begin{tabular}{|c|c|c|c|c|c|}
\hline \multirow{2}{*}{ Formulation } & \multirow{2}{*}{ Days } & \multirow{2}{*}{ Physical Appearance } & \multicolumn{3}{|c|}{ Percentage Drug content (\%) } \\
\hline & & & $4^{\circ} \mathrm{C}$ & $25^{\circ} \mathrm{C}$ & $45^{\circ} \mathrm{C}$ \\
\hline \multirow{5}{*}{2} & First day & $\begin{array}{l}\text { Stable Suspension of } \\
\text { white color }\end{array}$ & \multicolumn{3}{|c|}{97.659} \\
\hline & Second day & $\begin{array}{c}\text { Stable Suspension of } \\
\text { white color }\end{array}$ & 95.241 & 92.389 & 90.459 \\
\hline & Seventh day & $\begin{array}{l}\text { Stable Suspension of } \\
\text { white color }\end{array}$ & 91.739 & 89.519 & 85.217 \\
\hline & Fourteenth day & $\begin{array}{l}\text { Stable Suspension of } \\
\text { white color }\end{array}$ & 90.422 & 85.033 & 79.621 \\
\hline & Twenty first day & $\begin{array}{l}\text { Stable Suspension of } \\
\text { white color }\end{array}$ & 88.019 & 82.105 & 75.912 \\
\hline \multirow{5}{*}{3} & First day & $\begin{array}{c}\text { Stable Suspension of } \\
\text { white color }\end{array}$ & \multicolumn{3}{|c|}{98.901} \\
\hline & Second day & $\begin{array}{c}\text { Stable Suspension of } \\
\text { white color }\end{array}$ & 96.415 & 94.792 & 91.929 \\
\hline & Seventh day & $\begin{array}{l}\text { Stable Suspension of } \\
\text { white color }\end{array}$ & 93.901 & 90.597 & 88.271 \\
\hline & Fourteenth day & $\begin{array}{c}\text { Stable Suspension of } \\
\text { white color }\end{array}$ & 91.849 & 88.692 & 85.406 \\
\hline & Twenty first day & $\begin{array}{l}\text { Stable Suspension of } \\
\text { white color }\end{array}$ & 89.106 & 85.952 & 81.002 \\
\hline
\end{tabular}




\section{CONCLUSION}

Nanosponges loaded with naproxen sodium were formulated via emulsion solvent evaporation method. 11 trial formulation were further prepared and analyzed for post characterization. The test included calculation of viscosity; particle size; poly dispersity index and zeta potential. Among all the trial formulation only NS2 and NS3 were chosen for stability studies and diffusion studies by Franz diffusion cell. Results indicated the high drug loading efficacy and excellent release profile of drug. The above mentioned data verify the effective use of naproxen sodium loaded nanosponges. Nanosponges can also be combined in the form of hydrogel and analyzed for effective applications. The gap of the study involves more stability study on formulation and in-vivo characterization.

\section{REFERENCES}

1. Cavalli R, Trotta F, Tumiatti W. Cyclodextrin-based nanosponges for drug delivery. J Incl Phenom Macrocycl Chem. 2006; 56(1-2):209-13.

2. Silva GA. Nanotechnology applications and approaches for neuroregeneration and drug delivery to the central nervous system Ann. N. Y. Acad. Sci. 2010; 1199 (1):221-30.

3. Calixto GM, Bernegossi J, de Freitas LM, Fontana CR, Chorilli M. Nanotechnology-Based Drug Delivery Systems for Photodynamic Therapy of Cancer: A Review. Molecules. 2016; 21(3):342.

4. Brys AK, Gowda R, Loriaux DB, Robertson GP, Mosca PJ. Nanotechnology-based strategies for combating toxicity and resistance in melanoma therapy. Biotechnol. Adv. 2016; 34(5):565-77.

5. Beik J, Abed Z, Ghoreishi FS, Hosseini-Nami S, Mehrzadi S, Shakeri-Zadeh A, et al. Nanotechnology in hyperthermia cancer therapy: From fundamental principles to advanced applications. J. Control. Release. 2016; 235:205-21.

6. Bolmal UB, Manvi F, Rajkumar K, Palla SS, Paladugu A, Reddy KR. Recent advances in nanosponges as drug delivery system. Int $\mathrm{J}$ Pharm Sci Nanotechnol. 2013; 6:1934-44

7. Patel E, Oswal R. Nanosponge and micro sponges: a novel drug delivery system. Int J Res Pharm Chem. 2012; 2(2):237-44.

8. Szejtli J. Cyclodextrin complexed generic drugs are generally not bio-equivalent with the reference products:therefore the increase in number of marketed drug/cyclodextrin formulations is so slow. J Incl Phenom Macrocycl Chem 2005; 52(1-2):1-11.

9. Sharma R, Pathak K. Polymeric nanosponges as an alternative carrier for improved retention of econazole nitrate onto the skin through topical hydrogel formulation. Pharm. Dev. Technol.

2011; 16(4):367-76.

10. Trotta F, Cavalli R, Tumiatti W, Zerbinati $O$, Roggero $C$, Vallero R. Ultrasound-assisted synthesis of cyclodextrin-based nanosponges. Google Patents. 2008.

11. Aldawsari HM, Badr-Eldin SM, Labib GS, El-Kamel $\mathrm{AH}$. Design and formulation of a topical hydrogel integrating lemongrass-loaded nanosponges with an enhanced antifungal effect: in vitro/in vivo evaluation. Int J Nanomedicine. 2015; 10:893-902.

12. Jilsha G, Viswanad V. Nanosponge loaded hydrogel of cephalexin for topical delivery. Int. J. Pharm. Sci. Res. 2015; 6(7):2781.

13. Selvamuthukumar $S$, Anandam $S$, Krishnamoorthy K, Rajappan M. Nanosponges: A novel class of drug delivery system-review. J. Pharm. Pharm. Sci. 2012; 15(1):103-11.

14. Salopek B, Krasic D, Filipovic S. Measurement and application of zeta-potential. Rud.-geol.-naft. zb. 1992; 4(1):147-151.

15. Kaur M, Kaur G, Kaur H, Sharma S. Overview on stability studies. International Journal of Pharmaceutical, Chemical \& Biological Sciences. 2013; 3(4): 1231-1241.

16. Osmani $A M, R$ Bhosale $R$, Hani $U$, Vaghela $R, K$ Kulkarni P. Cyclodextrin based nanosponges: impending carters in drug delivery and nanotherapeutics. Curr. Drug ther. 2015; 10(1):3-19.

17. Shende P, Desai D, Gaud RS. Hybrid Nanosponges. Nanosponges: Synthesis and Applications. 2019; 173-92.

18. Pandey PJ. Multifunctional nanosponges for the treatment of various diseases: A review. Asian Journal of Pharmacy and Pharmacology. 2019; 5(2):235-48.

19. Abbas N, Irfan M, Hussain A, Arshad MS, Hussain SZ, Latif S, et al. Development and evaluation of scaffold-based nanosponge formulation for controlled drug delivery of naproxen and ibuprofen.Trop. j. pharm. res. 2018; 17(8):1465-74.

20. Kapileshwari GR, Barve AR, Kumar L, Bhide PJ, Joshi M, Shirodkar RK. Novel drug delivery system of antifungal drug-Formulation and characterisation. J Drug Deliv Sci Technol. 2019; 55:101302. 